\title{
The Investigation of the Effects of the Transesterification Reaction Temperature on the Biodiesel Production Rate: Poultry Fats as a Feedstock
}

\author{
Ribwar K. Abdulrahman ${ }^{\# 1}$, Saif T. Manji ${ }^{\# 2}$, Soran D. Jalal ${ }^{\# 3}$ \\ ${ }^{\# 1}$ Assisstant Lecturer, ${ }^{\# 2}$ Lecturer,${ }^{\# 3}$ Assisstant Lecturer, Chemical Engineering Department, Faculty of Engineering, Koya \\ University \\ Kurdistan Region, Iraq
}

\begin{abstract}
Nowadays, Energy is considered as one of the most important requirements for the economic development for any country. Indeed, almost all life and economic sectors are depended on energy for instanced agriculture, industry, transport and domestic. In fact, several oil and gas reservoirs are depleted every day around the world due to the excessive consumption of fossil fuels; for instance petroleum and coal emit high quantities of carbon dioxide and other toxic gases to the environment and will lead to global warming phenomenon. Therefore, there is a need to explore alternative energy resources which possess trusted properties and heating value. Biodiesel can be considered as quite trusted fuel because of many advantages for instance, reduce the global worming phenomenon and can be produced from cheap feed stocks. Indeed, biodiesel could be produced from many biological resources for example, vegetable oils \& animal fats. Thus, this work is aimed to produce a trusted biodiesel from poultry fats and investigate the effects of reaction temperature on the biodiesel yield. Moreover, the study has investigated several process parameters for instance, amount of catalyst and amount of methanol on biodiesel production yield. The produced biodiesel is also subjected into several laboratory tests for example, density, viscosity and cetane value and the results have been compared well with ASTM standards. Indeed, it has been found that it so possible to produce biodiesel from poultry fats. Moreover, it has also found that the transesterification reaction the temperature has huge effects on the biodiesel yield amount and it should be maintained within the range of $(45 \text { to } 65)^{\circ} \mathrm{C}$.
\end{abstract}

Keywords - Biodiesel, bio-fuel, renewable energy, chicken fat, process optimization, transesterification reaction, flash point.

\section{INTRODUCTION}

The demand for energy in recent decade has been dramatic. Moreover, energy is contributed in any country economy and it is essential in several life aspects for example: transportation, industry and agriculture. Furthermore, Biodiesel can be considered the most important sustainable energy in recent decade as well as the future [1], [2]. Biodiesel received huge attention worldwide to be used as alternative fuel for diesel engines. Moreover, it has several advantages over petroleum diesel for example, reduces the demand of petroleum fuels, nontoxic and reduces the global climate changes and environmental pollution. Furthermore, it has many advantages for example; biodiesel engines produce less $\mathrm{CO}, \mathrm{HC}$ and particulate emissions than petroleum diesel fuelled engines [1], [3], [5]. Indeed, biodiesel could be used directly in some specific diesel engines [3], [4]. However, it should be blended with petroleum diesel, if it is required to be used in normal diesel engine. As a result, biodiesel blends can be used in diesel engines without any major modification. Many researchers have indicated that the biodiesel is quite close to diesel fuel. Indeed, biodiesel could be produced from vegetable oils and animal fats as well. Moreover, biodiesel is also produced from grape seed oil and waste cooking oil [2], [5]. Using high quality virgin oils makes biodiesel more expensive than diesel fuel [7]. Therefore it is so important to use low cost feedstock. The use of vegetable oil leads to shortage of food while, on the other hand, animal fat which is considered as hazardous for human health [6] can be exploited as a feedstock for biodiesel production via a three step transesterification reversible reaction that converts the initial triglycerides into a mixture of Fatty acid methyl ester and glycerol in the presence of a catalyst usually homogeneous or heterogeneous. Alcohol for example, ethanol and methanol can be used in the transesterification reaction [8], [9]. Furthermore, many types could be used in this reaction for example, hydrochloric acid and sodium hydroxide and potassium hydroxide [1], [7]. Moreover, animal fats and restaurant waste oils are appealing feedstock to produce biodiesel. Moreover, the cost of virgin vegetable oil is about two times more than that of animal fat. Therefore the price of feedstock can be reduced about $50 \%$ with using low grade animal fat [7]. Moreover, animal fats could be obtained for free at slighter houses. The fats with high FFA cannot be converted to biodiesel using alkaline catalysts which have been used with good results for vegetable oils. The free fatty acids react with an alkaline catalyst and thus soaps are produced. Moreover, many studies have shown that chicken fat is a promising feedstock for biodiesel production [1], [7]. Therefore, this study chicken fat is used to produce biodiesel. The process optimization of the transesterification reaction has investigated with different methanol/oil ratio and catalyst amount. The obtained ester was characterized by determining its fuel properties according to standard test methods. Moreover, this study investigates the effects of reaction temperature on the biodiesel yield. Indeed, a higher reaction temperature could decrees the viscosity of the oil or fat and result an increase in reaction rate as more energy is being supplied for the reaction to occur [1]. Thus, the yield of biodiesel product could be improved. Moreover, the reaction rate depends on the reaction temperature [1], [6].

\section{Methodology AND EXPERIMENTAL WorK}

Firstly, the poultry fat collected from a local source (Fig. 1). The chicken fats have been cleaned with deionized water. 
Furthermore, the fat melted at $(65-70)^{\circ} \mathrm{C}$. The melted fat has been filtrated to remove any impurities. Indeed, it is quite important to determine the free fatty acid (FFA) of the chicken fat in order to use the accurate catalyst amount at the transesterification reaction. Furthermore, the free fatty acid (FFA) has been determined and found to be $1.8 \mathrm{mg}$ of $\mathrm{KOH} / \mathrm{gm}$ of the chicken fat. Indeed, many researchers have indicated that the prettification step is not needed if the acid value is lower than $2 \%$ [7].

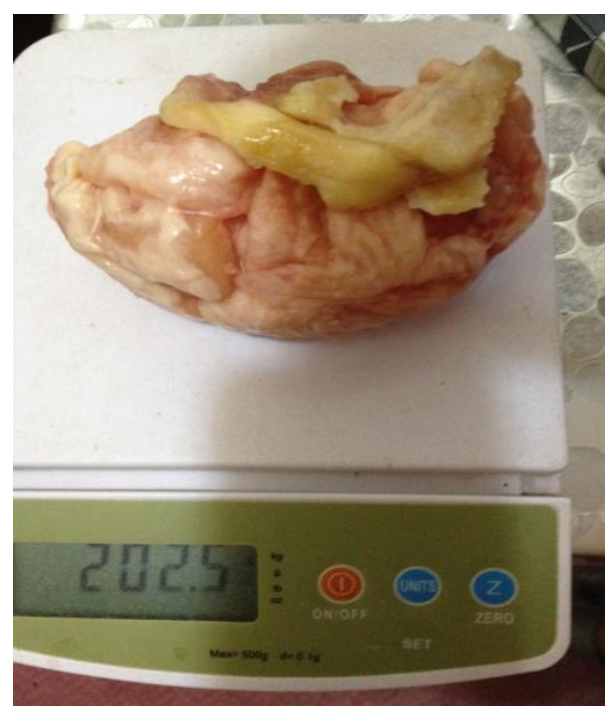

Fig. 1 Waste chicken fat

Hence alkali was used for the transesterification of chicken fat. The experiment was conducted in $250 \mathrm{ml}$ flasks. Alkali transesterification reaction has been adopted to produce the biodiesel from the meted fat. The calculated amount of $\mathrm{KOH}$ has been dissolved with the needed amount of methanol. This liquid has been introduced into the melted chicken fat in a specific flask. The reaction has been done at $60^{\circ} \mathrm{C}$ and for 30 and $60 \mathrm{~min}$. After the reaction was completed for melted chicken fat, the reaction mixture was allowed to be separated into two layers by using a separator funnel. Fig. 2 shows the separator funnel which contents the reaction product. After a short period of time, the mixture is separated into two phases. The heavy phase, distinguished with red color, contains the impurities and glycerol. The esters obtained at the light phase at the top of the separator funnel. Then, the produced biodiesel has been washed two times by hot water.

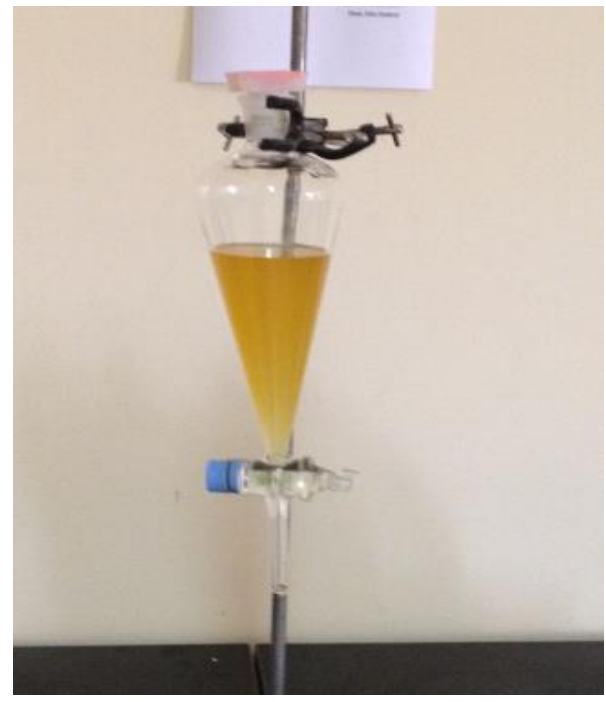

Fig. 2 Separator funnel which content the reaction product

\section{RESULTS AND DISCUSSION}

The transesterification reaction is done by using the chicken fats. Table 1 shows some physical properties of produced biodiesel while Fig. 3 shows the specific gravity test.

TABLE 1

PHYSICAL PROPERTIES OF PRODUCED BIODIESEL

\begin{tabular}{|l|l|l|}
\hline Properties & $\begin{array}{l}\text { Produced } \\
\text { biodiesel }\end{array}$ & $\begin{array}{l}\text { ASTM Standers } \\
\text { for Biodiesel }\end{array}$ \\
\hline Density $15^{\circ} \mathrm{C} \mathrm{kg} / \mathrm{m}^{3}$ & 883 & $860-900$ \\
\hline Viscosity $40^{\circ} \mathrm{Cmm}^{2} / \mathrm{s}$ & 5.885 & $1.9-6$ \\
\hline Cetane Number & 74 & 40 \\
\hline Flash point ${ }^{\circ} \mathrm{C}$ & 106 & 54 \\
\hline
\end{tabular}

The methanol/oil molar ratio could be considered the most important parameter that affects the biodiesel yield. Thus, the process optimization for biodiesel production is achieved by using several methanol/oil ratios. Fig. 4 shows the relationship between different methanol/oil ratio and the yield percent of the biodiesel. It seems from Fig. 4 that the yield percentages increase by increasing the amount of methanol. However, the reaction reaches equilibrium at methanol/oil ratio about 7:1. Hence, it can argue that using of ratio of methanol/oil ratio within (6:1 to $7: 1)$ can achieve the optimal biodiesel production amount. 


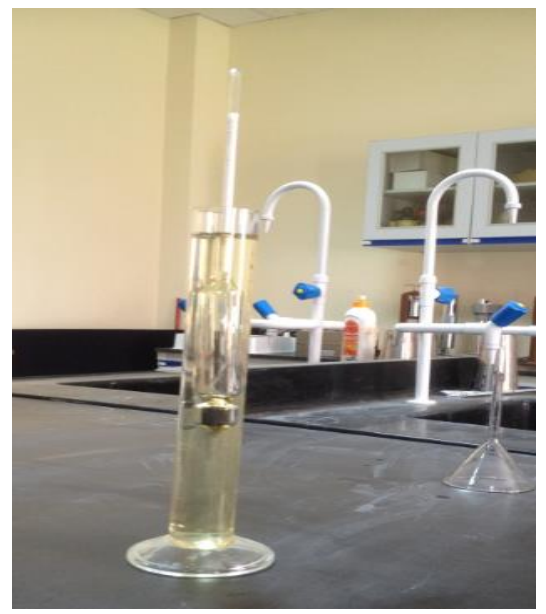

Fig. 3 The specific gravity test

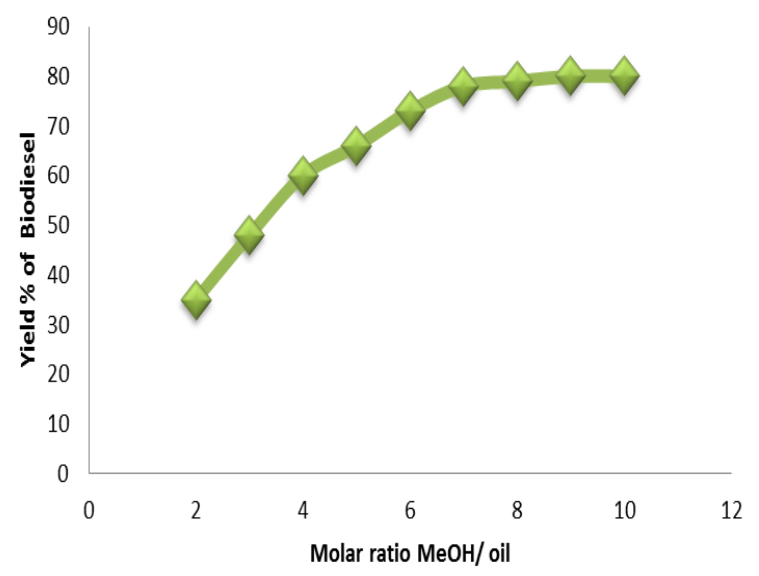

Fig. 4 The relationship between the molar ratio of $\mathrm{MeOH} / \mathrm{oil}$ and biodiesel yield $\%$

Indeed, the transesterification reaction temperature may consider as a quite important factor to achieve the transesterification reaction. In fact, a higher reaction temperature can decrees the viscosity of the fat and result in an increase in reaction rate. However, elevated reaction temperatures may reduce the biodiesel yield. Figure 5 shows the relationship between the reaction temperature and biodiesel yield $\%$ at $60 \mathrm{~min}$ reaction time at 7:1 methanol/ oil ratio, $0.38 \mathrm{gm} \mathrm{KOH}, 60 \mathrm{~min}$ reaction time and $700 \mathrm{rpm}$ agitation speed. It seems from this figure that the reaction temperature should be kept within the range of $(45 \text { and } 65)^{\circ} \mathrm{C}$. Moreover, $60{ }^{\circ} \mathrm{C}$ may consider the optimal reaction temperature for this work.

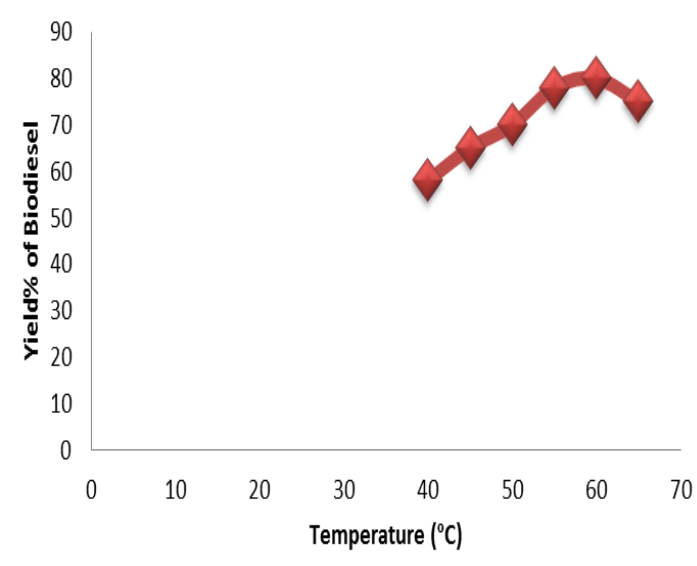

Fig. 5 The relationship between the reaction temperature and biodiesel yield $\%$ at $60 \mathrm{~min}$ reaction time

\section{CONCLUSION}

In conclusion, this work attempts to produce biodiesel from chicken fat and to study the effects of the transesterification reaction temperature on the biodiesel yield. Moreover, it can be argued that it is possible to produce biodiesel from poultry fats by using transesterification reaction method. Moreover, the process optimization is also done for many parameters for instance, reaction temperature and methanol/oil molar ratio. It can be argued that using methanol/ oil ratio about 7:1 can achieved accepted biodiesel yield. It can also argue that the transesterification reaction temperature is one of the most important process parameters and possess direct effects on the on the biodiesel yield amount. Indeed, it has been observed that the transesterification reaction temperature should be maintained within the range of (45 to 65$)^{\circ} \mathrm{C}$ and the optimal reaction temperature for this study was about $60^{\circ} \mathrm{C}$ at methanol/ oil ratio 7:1, $0.38 \mathrm{gm} \mathrm{KOH}$ and reaction time 60 min and $700 \mathrm{rpm}$ agitation speed. However, it is recommended that to achieve more works and studies before installing biodiesel plant to be used for commercial biodiesel production.

\section{REFERENCES}

[1] A. Sarin, Biodiesel: Production and Properties. Dorchester: Royal Society of Chemistry, 2012

[2] E. Ramalho, J. Filho, A. Albuquerque, S. Oliveira, E. Cavalcanti, L. Stragevitch, I. Santos, and A. Souza, "Low temperature behavior of poultry fat biodiesel: diesel blends", Fuel, vol. 93, pp. 601-605, Jan. 2012

[3] M. Balat and H. Balat, 'Progress in biodiesel processing', Applied Energy, vol. 87, pp. 1815-1835. Jan. 2012.

[4] V. Marulandab, G. Anitescua, \& L. Tavlaridesa, "Investigations on supercritical transesterification of chicken fat for biodiesel production from low-cost lipid feedstocks', The Journal of Supercritical Fluids, vol. 54, pp. 53-60, Jan. 2010.

[5] M. Ahmad, Practical Handbook on Biodiesel Production and Properties. Boca Raton: CRC Press, 2010.

[6] A. Scragg, Biofuels: Production, Application and Development, Oxfordshire: CABI co. 2009.

[7] I. Panneerselvam, and R. Parthiban, "Poultry Fat: A Cheap and Viable Source for Biodiesel Production", International Conference on Environmental Science and Technology, 2010, pp. 42-45. 